Journal of Materials and Environmental Sciences ISSN : 2028-2508

CODEN : JMESCN

Copyright $\odot$ 2017,

University of Mohammed Premier

Oujda Morocco
J. Mater. Environ. Sci., 2017, Volume 8, Issue 12, Page 4475-4486

http://www.jmaterenvironsci.com

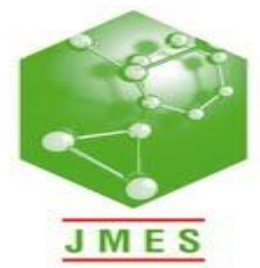

\title{
The study of the aqueous extract of leaves of Pancratium Foetidum Pom as: Characterization of polyphenols, flavonoids, antioxidant activities and Eco- friendly corrosion inhibitor
}

\author{
H. Bendaif ${ }^{1 *}$, A. Melhaoui ${ }^{1}$, A. Bouyanzer ${ }^{2}$, B. Hammouti ${ }^{2}$, Y. El Ouadi ${ }^{2}$ \\ ${ }^{1}$ LCOMPN-URAC25, Faculty of Sciences, laboratory of Organic Chemistry, Macromolecular and Natural Products, \\ University Mohamed 1st University, BP 524, 60000 Oujda, Morocco \\ ${ }^{2}$ Laboratoire de Chimie Analytique Appliquée Matériaux et Environnement (LCA2ME-URAC18), Faculté des Sciences, B.P. \\ 717, 60000 Oujda, Morocco
}

Received 13May 2017, Revised 30Jul 2017, Accepted 01 Aug 2017

Keywords

$\checkmark$ Pancratium foetidum Pom;

$\checkmark$ Aqueous extracts;

$\checkmark$ Antioxidant activities;

$\checkmark$ Green corrosion;

$\checkmark$ Electrochemical measurements

H. Bendaif

hajar.bendaif@gmail.com

Y. El Ouadi

elouadi.yassir@gmail.com

$+212666070528$

\begin{abstract}
Antioxidant activity studied by using the DPPH radical trapping test. For this purpose, the phenols and flavonoids compounds were dosed. Quantitation of the phenolic and flavonoid compounds of the aqueous extract to the solvent (diethyl ether and ethyl acetate) was determined by spectrometry. Finally, the DPPH trapping activity of the extracts increased in the order of: diethyl ether fraction <ethyl acetate fraction <ascorbic acid.The inhibition of mild steel in the $1 \mathrm{M}$ hydrochloric acid solution is also studied. The aqueous extract of leaves of Pancratium Foetidum Pom, was carried out by potentiodynamic polarization, electrochemical impedance spectroscopy and weight loss studies. The results obtained show that the inhibition efficiency increases with the increase in inhibitor concentration and the variation in the inhibitory efficiency depends mainly on the type and nature of the substituents presents in the mixture (aqueous extract) to reach $98 \%$ To $1 \mathrm{~g} / \mathrm{L}$.
\end{abstract}

\section{Introduction}

The family of Amaryllidaceae resembles a family of monocotyledonous plants. They include more than 800 species in 60 genus including Galanthus, Leucojum, Narcissus and Pancratium. They are herbaceous plants, mainly bulbous, perennial, with deciduous leaves, and inferior ovary, they are suitable for temperate to tropical regions. Amaryllidaceae are herbaceous plants with an erect stem; the leaves often rectinerves, the flowers actinomorphs. The ovary is inferior (adherent); Sometimes a crown or paracorolle evolves from the perianth [1]. Pancratium foetidum Pom belongs to Amaryllidaceae family, it's a plant endemic to north west of morocco and east of Alger according to Jahandiez and Maire [2].

Corrosion is the progressive destruction of a material due to its reaction with the environment, causing a slow, regular and irreversible deterioration of the metal. This major industrial problem has attracted many researchers in recent years. Before, it was known that the main strategy to prevent electrochemical corrosion is the isolation of metals from corrosive agents. Currently, the use of inhibitors is one of the most practical methods for corrosion protection. Considerable efforts have been made to find suitable compounds to be used as corrosion inhibitors in various corrosive media to stop or retard the corrosion of a metal. Recently, several studies have been carried out on the inhibition of corrosion of metals by synthetic organic molecules [3-7]. In spite of the high efficiency of 
these synthesized organic compounds, they cause side effects on the environment, hence the need to replace them with biodegradable inhibitors, which are eco-compatible with the environment and which do not have side effects on the living being [8-11].

Several questions have arisen concerning the safety of chemicals, used in medicine or in the food industry under the action of oxygen free radicals which lead to changes in taste, odor, color and consequently to the loss of food quality and safety. So, it is essential to look for new effective and non-harmful antioxidant substances.

Despite the importance of oxygen in life, it can be toxic by itself and by the formation of free radicals, reactive oxygen species (ROS) which appear under the action of UV rays, radiation ionizing, numerous transition metals and thus during various enzymatic reactions. These ROS have numerous deleterious effects, causing premature aging, cardiovascular problems, atherosclerosis, diabetes and cancers [12]. Lipid oxidation is responsible for the formation of undesirable chemical compounds, resulting from unpleasant tastes and odors, reducing the quality of food [13]. Therefore, controlling oxidation is essential to manage the evolution of biological systems in their complexity, particularly in the case of foods whose degradation can have consequences for food safety[14]. To inhibit these unwanted processes, natural antioxidant additives are used [15-17]. The aim of the second part of this study is to evaluate the antioxidant activity of three bioactive substances (alkaloids, flavonoids and polyphenols) of the aqueous extract of leaves of Pancratium Foetidum Pom.

\section{Experimental Section}

2. 1. Plant material

Pancratium foetidum plant was collected from Saïdia-Oujda, Morocco in May 2015. The plant was cleaned, dried and kept in dry place at the laboratory. The systematics of PancratiumFoetidumPom is as follow:

Class: Monocotyledons

Order: Albumins

Family: Amaryllidaceae

Genus: Pancratium

Species: Foetidum

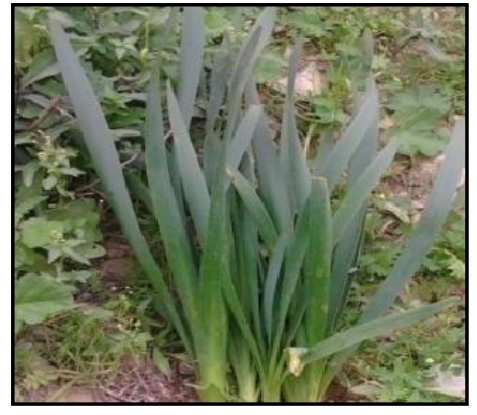

Figure 1: Leaves of Pancratium foetidum Pom (LPFP)

\subsection{Aqueous extract}

The aqueous extract of the leaves of Pancratium Foetidum (LPFP) is obtained by a solid / liquid extraction by decoction.

- $100 \mathrm{~g}$ of leaves of Pancratium Foetidum (LPFP) are placed in a boiling flask with $100 \mathrm{ml}$ of water.

- Keep the mixture boiling for three hours in a soxhlet;

- At the end of the decoction, filter, recover and allow the solution to cool.

It is stated that the leaves of the studied plant are poor in essential oil. The reason why its aqueous extract was used.

\subsection{Fractionating the aqueous extract $[15,17]$}

The mixture is extracted after filtration by two solvents of different polarity namely, ethyl acetate and diethyl ether, polarity indices respectively 0.58 and 0.38 :

A sample of $100 \mathrm{ml}$ of the extract recovered by steam distillation is hydrolyzed with $40 \mathrm{ml} 2 \mathrm{~N}$ HClbath at $373 \mathrm{~K}$ for one hour, at the end of this treatment, plant debris clusters are formed and extract aqueous recovered is filtered and then mixed in a separating funnel and shaken thoroughly with diethyl ether or ethyl acetate. After settling in an ampoule, the upper organic phase is collected in an Erlenmeyer flask, the extraction is repeated 3 times with solvent renewal. The latter is due evaporated after drying the organic phase with anhydrous sodium sulfate, and the resulting extract is considered as the fraction of diethyl ether or ethyl acetate. The fractions thus obtained were stored in glass vials and then kept at a temperature of 277 to $278 \mathrm{~K}$ prior to analysis. 


\subsection{Determination of total phenolics contents}

Polyphenols are estimated by various methods such as the method of Prussian blue [18], but the most used is the Folin-Ciocalteu. This consists of a mixture of phosphotungstic acid $\left(\mathrm{H}_{3} \mathrm{PW}_{12} \mathrm{O}_{40}\right)$ and phosphomolybdic acid $\left(\mathrm{H}_{3} \mathrm{PMo}_{12} \mathrm{O}_{40}\right)$; it is reduced by the phenols in a mixture of the blue oxides of tungsten and molybdenum [19].

$1 \mathrm{ml}$ of Folin reagent (diluted 10 times in distilled water) was added to $200 \mu \mathrm{lof}$ sample or standard (gallic acid) with suitable dilutions in distilled water, after $4 \mathrm{~min}, 800 \mu \mathrm{l}$ of a solution sodium carbonate $(75 \mathrm{mg} / \mathrm{ml})$ are added to the reaction medium. After 45 minutes incubation at room temperature, the absorbance of the resulting solution is measured at $760 \mathrm{~nm}$. The same procedure was also applied to the standard solutions of gallic acid, and a standard curve was obtained. The concentrations of phenolic compounds expressed as $\mu$ ggallic acid equivalent per mg of extract were calculated according to the standard gallic acid graph.

All experiments were performed in triplicate assays, and gallic acid equivalent values were reported as $\mathrm{X}$ (average) $\pm \mathrm{SD}$ (standard deviation) of triplicates.

\subsection{Determination of total flavonoids contents}

Quantification of flavonoids in extracts of leaves of Pancratium Foetidum Pom were performed by the method of aluminum trichloride [20,21].

$1 \mathrm{ml}$ of sample or standard (dissolved in methanol) was added to $1 \mathrm{ml}$ of the solution of $\mathrm{AlCl}_{3}(2 \%$ in methanol). After 30 minutes of reaction, the absorbance is read at $415 \mathrm{~nm}$. The concentrations of flavonoid compounds expressed as $\mu$ grutin equivalent per mg of extract were calculated according to the standard rutin graph. All experiments were performed in triplicate assays and rutin equivalent values were reported as $\mathrm{X} \pm \mathrm{SD}$ of triplicates.

\subsection{Antioxidant activity}

We use 1,1-diphenyl-2-picrylhydrazyl(DPPH) to measure the free radical-scavenging activities of solvent extracts, as described by Hatano et al. [22]. The stable free radical DPPH (deep violet color) converts to 1,1diphenyl-2-picrylhydrazine with discoloration by reaction with the antioxidants.

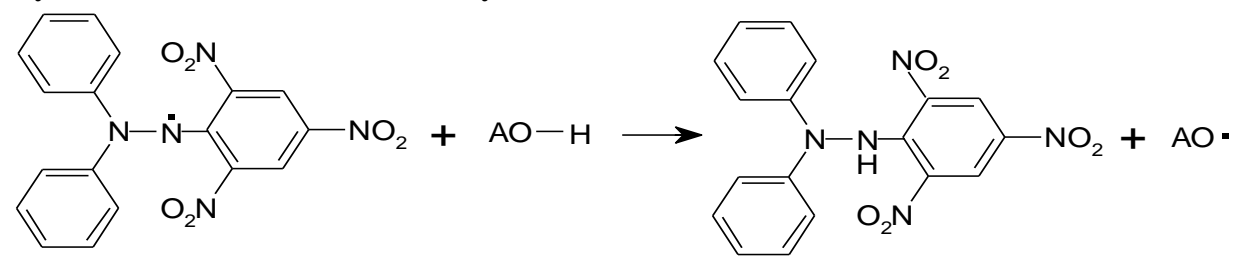

$\mathrm{DPPH}$

\section{DPPHH}

Where: (AO-H) represents a compound capable of yielding hydrogen to DPPH radical (violet) to transform it into picryldiphenyl hydrazine (yellow)[23].

The concentrations of the samples and standars studied are prepared in ethanol. Concentrations (between 0.2 and $2 \mu \mathrm{g} / \mathrm{ml}$ ) were added to $3.9 \mathrm{ml}$ of a solution of DPPH radicals in ethanol.

The mixture was allowed to stand at room temperature for 30 minutes in the dark. The absorbance was measured at $517 \mathrm{~nm}$ against a blank. The radical-scavenging activity was expressed as percentage of inhibition (I\%) according to the following formula [24]:

$$
\mathrm{I}(\%)=100 *\left(\mathrm{~A}_{\text {control }}-\mathrm{A}_{\text {sample }}\right) / \mathrm{A}_{\text {control }}
$$

Where $\mathrm{A}_{\text {control }}$ is the absorbance of the control reaction and $\mathrm{A}_{\text {sample }}$ is the absorbance of the test compound. The sample concentration providing $50 \%$ inhibition $\left(\mathrm{IC}_{50}\right)$ was calculated from the graph of inhibition percentage against sample concentration. Tests were carried out in triplicate. Ascorbic acid was used as a positive control.

\subsection{Preparation of test specimens}

The Mild Steel specimens tested in this present paper, are prepared with a composition (in\% by weight) $(0.21 \%$ $\mathrm{C}, 0.38 \% \mathrm{Si}, 0.09 \% \mathrm{P}, 0.01 \% \mathrm{Al}, 0.05 \% \mathrm{Mn}, 0.05 \% \mathrm{~S}$ ).

The mild steel samples were prepared prior immersion in the tested solutions by polishing with SiC paper up to 1200 grade, washing with distilled water and then degreased with alcohol, washed again with distilled water then dried it by used filter papers. The electrolyte is a solution of $\mathrm{HCl} 1 \mathrm{~mol} / \mathrm{L}$, prepared using double distilled water. 


\subsection{Weight loss measurements}

The gravimetric test is based on the immersion of the mild steel samples, in $100 \mathrm{ml}$ of a $1 \mathrm{M} \mathrm{HCl} \mathrm{solution}$ containing the inhibitor (aqueous extract) at different concentrations, after be degreased, polished and weighed. Immersion is subjected to a temperature of $308 \mathrm{~K}$ to 6 hours.

Temperature corrosive environment is a factor that can affect the efficacy of inhibiting it. Given the importance of this factor, we performed tests of mass loss of steel in $1 \mathrm{M} \mathrm{HCl}$ with and without addition of the inhibitor at different temperatures between 318 and $348 \mathrm{~K}$.

\subsection{Electrochemical measurements}

The corrosion cell involving three electrodes, mild steel as working electrode, saturated calomel electrode (SCE) as reference electrode and a platinum wire used as counter electrode. The exposed area of working electrode to solutions was $1 \mathrm{Cm}^{2}$.

The major electrochemical techniques used in this study are Tafel plots polarizations (TP) and Eelectrochemical impedance spectroscopy (EIS).

The polarization curves were recorded using a potentiostat type PGZ Volta Lab 301 to a scan rate of $1 \mathrm{mV} / \mathrm{Sec}$. The electrode of steel was maintained at the corrosion potential for 30 minutes and the following pre-polarized 800 to $-200 \mathrm{mV} / \mathrm{SCE}$ for $10 \mathrm{~min}$, all experiments were repeated three times at the desired temperature of $\pm 274 \mathrm{~K}$. Electrochemical impedance spectroscopy (EIS) was carried out with the same equipment used for the polarization measurements, leaving the frequency response analyzer out of consideration. Quasi-potentiostatic polarization curves were obtained using a sweep rate of $1 \mathrm{mV} / \mathrm{s}$. After the determination of steady-state current at a given potential, sine wave voltage $(10 \mathrm{mV})$ peak to peak, at frequencies between $100 \mathrm{kHz}$ and $10 \mathrm{mHz}$ was superimposed on the rest potential. Computer programs automatically controlled the measurements performed at rest potential after $30 \mathrm{~min}$ of exposure. All potentials were reported versus saturated calomel electrode (SCE). The impedance diagrams are given in the Nyquist representation.

All electrochemical studies were carried out with immersion time of 1 hour, with different inhibitory concentrations of aqueous extract of leaves of PancratiumFoetidumPom, at $308 \mathrm{~K}$.

Experiments are repeated three times to ensure the reproducibility.

\section{ResultatsAnd Discussion}

\subsection{Total phenolic and flavonoid contents of solvent extracts}

To determine the quantity of total phenols and flavonoids in the two fractions of aqueous extract of leaves of Pancratium Foetidum Pom, colorimetric methods (Folin-Ciocalteux and Aluminum Trichloride (AlCl3) are used).

Table 1: Determination of total polyphenols and flavonoids in both fractions extracts of leaves of Pancratium Foetidum Pom

\begin{tabular}{|c|c|c|c|}
\hline & Extract & $\begin{array}{c}\text { Polyphenols } \\
\text { in } \mu \text { gequivalent of gallic } \\
\text { acid per mg of extract }\end{array}$ & $\begin{array}{c}\text { Flavonoids } \\
\text { in } \mu \text { g equivalent of rutin } \\
\text { per mg of extract }\end{array}$ \\
\hline \multirow{2}{*}{$\begin{array}{c}\text { Leaves of } \\
\text { PancratiumFoetidumPom } \\
\text { (LPFP) }\end{array}$} & Fraction diethyl ether & $14 \pm 29$ & $10 \pm 0.2$ \\
\hline & Fraction ethyl acetate & $22 \pm 25$ & $17 \pm 1.6$ \\
\hline
\end{tabular}

The content of total phenols estimated by the Folin-Ciocalteu method for each extract fraction was reported in $\mu$ ggallic acid equivalent / $\mathrm{mg}$ of extract. The results show that ethyl acetate and diethyl ether fractions of aqueous extract of leaves of Pancratium Foetidum Pom have respectively moderate levels $(22 \pm 25$ and $14 \pm 29 \mu \mathrm{g} / \mathrm{mg}$ equivalent gallic acid per mg of extract). The flavonoid content determined by the method trichloride aluminum of each extract fraction was reported in $\mu \mathrm{g}$ equivalent rutin / $\mathrm{mg}$ of extract. The results reveal that ethyl acetate and diethyl ether fractions of aqueous extract of leaves of Pancratium Foetidum Pom have respectively a small

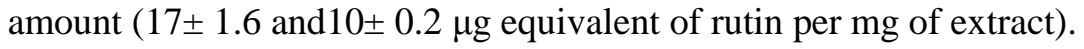


The determination of the quantity of the polyphenols and flavonoids in the two fractions of the aqueous extract of Pancratium Foetidum Pom, showed that the aqueous extract studied has a low content of polyphenols and flavonoids.

\subsection{Antioxidant Activity}

Table 2 gives the results of free radical scavenging activity of fraction diethyl ether, fraction ethyl acetate and Acid Ascorbic (positive control). According to the findings, it is noted that the DPPH scavenging activities (\%) were increased significantly with increasing the concentration of the studied samples from 0.2 to $2 \mu \mathrm{g} / \mathrm{mL}$.

Table 2:The antioxidant activity of the fractions (diethyl ether and ethyl acetate) of the aqueous extract of leaves of Pancratium Foetidum Pom (LPFP) at different concentrations

\begin{tabular}{|c|c|c|c|c|c|c|}
\hline Samples & Antic & Activi & & & & \\
\hline \multirow{3}{*}{ Diethylether fraction } & Concentrations of the extract $(\mu \mathrm{g} / \mathrm{ml})$ & 0.2 & 0.35 & 05 & 1 & 2 \\
\hline & Trapping Effect on DPPH (\%) & 6 & 13 & 18 & 26 & 31 \\
\hline & $\mathrm{DPPH} \mathrm{IC}_{50}(\mu \mathrm{g} / \mathrm{ml})$ & & & & & \\
\hline \multirow{3}{*}{ Ethyl acetate fraction } & Concentrations de l'extrait $(\mu \mathrm{g} / \mathrm{ml})$ & 0.2 & 0.35 & 0.5 & 1 & 2 \\
\hline & Trapping Effect on DPPH (\%) & 8 & 15 & 26 & 31 & 40 \\
\hline & $\mathrm{DPPH} \mathrm{IC}_{50}(\mu \mathrm{g} / \mathrm{ml})$ & & & & & \\
\hline \multirow{3}{*}{ Ascorbic acid } & Concentrations $(\mu \mathrm{g} / \mathrm{ml})$ & 0.2 & 0.35 & 0.5 & 1 & 2 \\
\hline & Trapping Effect on DPPH (\%) & 20 & 28 & 32 & 55 & 83 \\
\hline & $\mathrm{DPPH} \mathrm{IC}_{50}(\mu \mathrm{g} / \mathrm{ml})$ & & & & & \\
\hline
\end{tabular}

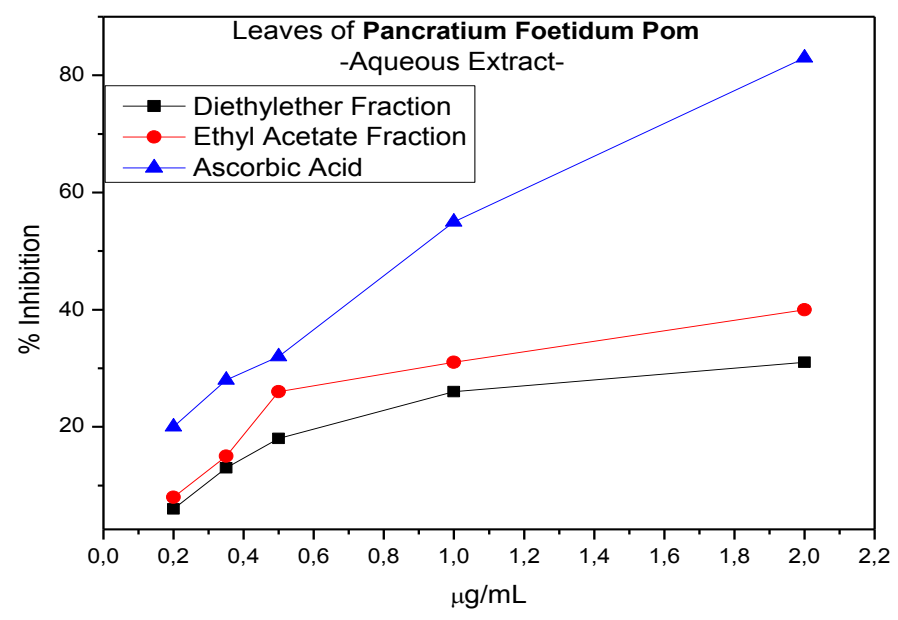

Figure 2: Antioxidant power of two fractions of the aqueous extract of leaves of Pancratium Foetidum Pom, (LPFP) OD reading after $30 \mathrm{~min}$ of incubation

According to (table 2), the antioxidant activity of both fraction (ethyl acetate and diethyl ether) of aqueous extract, is much lower than ascorbic acid. Although, ethyl acetate fraction isslightly greater than the diethyl ether fraction (Figure 2). This activity of the aqueous extract increases with the concentration, this is explained by the fact that the studied samples give hydrogen to DPPH who then converted to the color violet in yellow and absorbs less light. When the concentration is high, more antioxidants DPPH is reduced, so less it absorbs light passing through it. We can explain the moderate antioxidant activity of both fraction of aqueous extract of Pancratium Foetidum Pom leaves (LPFP), by the low content of polyphenols and flavonoids present in the aqueous extract of the plant studied. It is known that there is a relationship between the antioxidant activity and the content of 
polyphenols and flavonoids $[15,17]$, which explains the moderate antioxidant activity exhibited by our aqueous extract. This low activity can also be explained by the presence of the total alkaloids in PancratiumFoetidumPom [25]. The latter are known for their low antioxidant activities [26].

\subsection{Potentiodynamic polarization curves}

The potentiodynamic measurement results of mild steel in $1.0 \mathrm{M} \mathrm{HCl}$ solution without and with different range of inhibitor (aqueous extract of leaves of PancratiumFoetidumPom) concentrations were shown in (Figure 3). The polarization parameters namely corrosion current density $\left(\mathrm{I}_{\text {corr }}\right)$, corrosion potential $\left(\mathrm{E}_{\text {corr }}\right)$, anodic Tafel slope $\left(\beta_{\mathrm{a}}\right)$, cathodicTafel slope $\left(\beta_{\mathrm{c}}\right)$ and percentage inhibition efficiency $\left(\mathrm{E}_{\mathrm{I}} \%\right)$ were calculated from the Tafel curves and are given in Table 3. It can be observed that from Fig. 3, both the cathodic and anodic reactions were suppressed with the addition of inhibitor, which suggested that the inhibitor studiedreduced anodic dissolution and also retarded the hydrogen evolution reaction [7].

Table 3. It can be observed that from (Figure 3), both the cathodic and anodic reactions were suppressed with the addition of inhibitor, which suggested that the inhibitor studiedreduced anodic dissolution and also retarded the hydrogen evolution reaction [7].

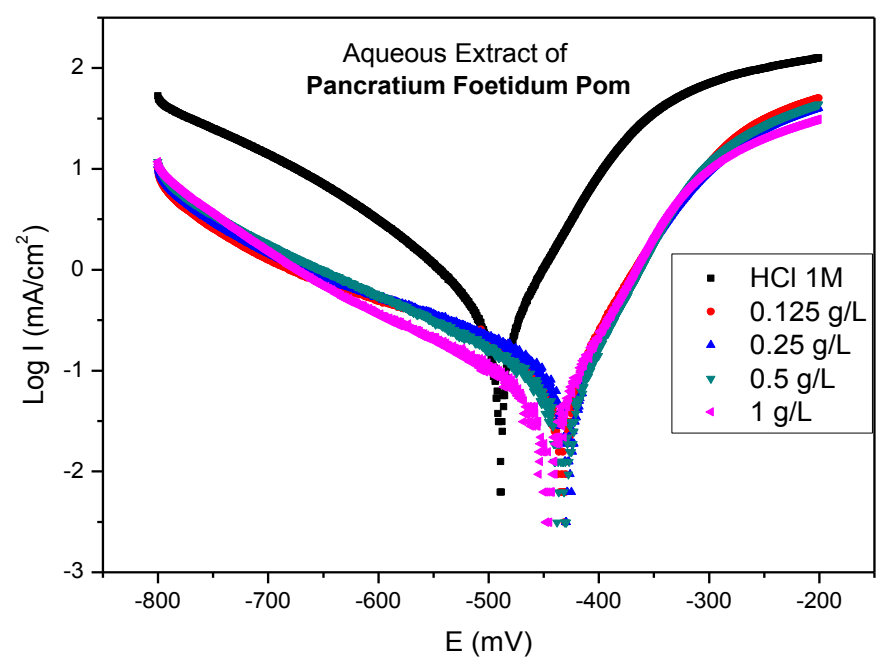

Figure 3: Tafel polarization curves in in $\mathrm{HCl} \mathrm{1Mwith} \mathrm{and} \mathrm{without} \mathrm{aqueous} \mathrm{extract} \mathrm{of} \mathrm{leaves} \mathrm{of}$ PancratiumFoetidumPom(LPFP) at different concentrations

The inhibition efficiency was evaluated from the measured $I_{\text {corr }}$ values using the following relationship: $\mathrm{E}_{\mathrm{I}}(\%)=\frac{I_{\text {corr }}-I_{\text {corr(i) }}}{I_{\text {corr }}} \times 100$

where $I_{\text {corr }}$ and $I_{\text {corr }(i)}$ are the corrosion current densities for steel electrode in the uninhibited and inhibited solutions, respectively.

Table 3: The electrochemical parameters for mild steel in $1.0 \mathrm{M} \mathrm{HCl}$ solution without and with different concentration of aqueous extract of leaves of PancratiumFoetidumPom (LPFP) at $308 \mathrm{~K}$

\begin{tabular}{|c|c|c|c|c|c|}
\hline Inhibitor concentrations & $\mathbf{- E}_{\text {Corr }}(\mathbf{m V})$ & $\begin{array}{c}\boldsymbol{\beta}_{\mathbf{a}} \\
(\mathbf{m V / d e c})\end{array}$ & $\begin{array}{c}\boldsymbol{\beta}_{\mathbf{C}} \\
(\mathbf{m V} / \mathbf{d e c})\end{array}$ & $\mathbf{I}_{\text {Corr }}\left(\mathbf{m A} / \mathbf{c m}^{\mathbf{2}}\right)$ & $\mathbf{E}_{\mathbf{I}}(\boldsymbol{\%})$ \\
\hline $\mathbf{H C l} \mathbf{1 M}$ & 490 & 74.8 & -147.7 & 0.5779 & - \\
\hline $\mathbf{0 . 1 2 5} \mathbf{g} / \mathbf{L}$ & 433 & 55.7 & -198.9 & 0.0678 & 88.27 \\
\hline $\mathbf{0 . 2 5} \mathbf{g} / \mathbf{L}$ & 428 & 51.7 & -194 & 0.0638 & 88.96 \\
\hline $\mathbf{0 . 5} \mathbf{~ g / L}$ & 428 & 48.3 & -159.1 & 0.0427 & 92.61 \\
\hline $\mathbf{1} \mathbf{~ g / L}$ & 447 & 52.3 & -145.8 & 0.0279 & $\underline{\mathbf{9 5 . 1 7}}$ \\
\hline
\end{tabular}


The corrosion potentials $\left(\mathrm{E}_{\text {corr }}\right)$ for the mild steel in the presence of aqueous extract are slightly shifted toward the positive potentials compared with the mild steel in $1.0 \mathrm{M} \mathrm{HCl}$. Both anodic and cathodic current densities were reduced in the presence of inhibitor which suggests a mixed-type inhibitor behavior [27].

It is clear from (Table 3), that after increasing the concentration of inhibitor, the inhibition efficiency increased, while the corrosion current density decreased due to adsorption of inhibitor on the mild steel surface. The minor shift in $\mathrm{E}_{\text {corr }}$ value $(62 \mathrm{mV})$ towards positive direction in the presence of inhibitor, as compared to the $\mathrm{E}_{\text {corr }}$ value in the absence of inhibitor indicates that aqueous extract of leaves of Pancratium Foetidum Pom (LPFP) act as mixed type inhibitor.

\subsection{Electrochemical impedance spectroscopy studies}

The Nyquist plots obtained from the EIS measurements for mild steel in $1.0 \mathrm{M} \mathrm{HCl}$ solutions at $308 \mathrm{~K}$ are shown in Fig. 4. The plots are characterized by a semicircle, which means the process was mainly controlled by capacitance and depressed semicircle reflects the surface in-homogeneity of structural or interfacial origin, such as those found in adsorption processes [28].

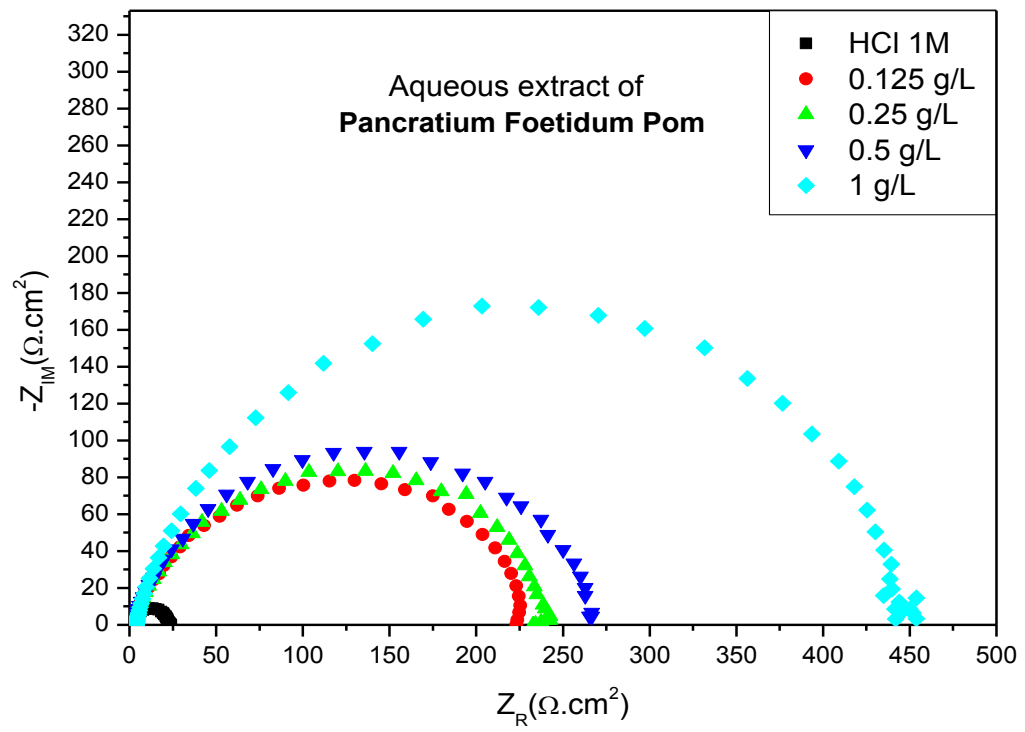

Figure 4: Nyquist plots recorded for mild steel in $1.0 \mathrm{M} \mathrm{HCl}$ solutions without and with differents concentrations of aqueous extract of leaves of Pancratium Foetidum Pom (LPFP)

The capacitive semicircle refers to the double layer capacitance and transfer resistance $\left(\mathrm{R}_{\mathrm{ct}}\right)$. The diameter of semicircle represents the value of transfer resistance $\left(\mathrm{R}_{\mathrm{ct}}\right)$ which indicates a decreasing trendy in corrosion rate. The charge transfer resistance values $\left(R_{c t}\right)$ was calculated from the difference between impedance values at lower and higher frequencies as suggested by Haruyama et al. [29]. The double layer capacitance $\left(\mathrm{C}_{\mathrm{dl}}\right)$ was obtained from the following equation:

$$
f\left(-Z_{\text {img }}\right)=\frac{1}{2 \pi C_{d l} R_{c t}}
$$

where $Z_{\mathrm{img}}$ is the frequency of maximum imaginary components of the impedance and $\mathrm{R}_{\mathrm{ct}}$ is the charge transfer resistances.

The calculated electrochemical parameters of EIS measurements are listed in Table 4.

The inhibition efficiency of the inhibitor was calculated from the charge transfer resistance values using the following equation:

$$
E_{R p} \%=\left(\left(\mathrm{R}_{\mathrm{ct}}-R_{\mathrm{ct}}^{0}\right) / \mathrm{R}_{\mathrm{ct}}\right) \times 100
$$

Where, $\mathrm{R}_{\mathrm{ct}}$ and $\mathrm{R}_{\mathrm{ct}}^{0}$ are the charge transfer resistance in absence and in presence of inhibitor, respectively. 


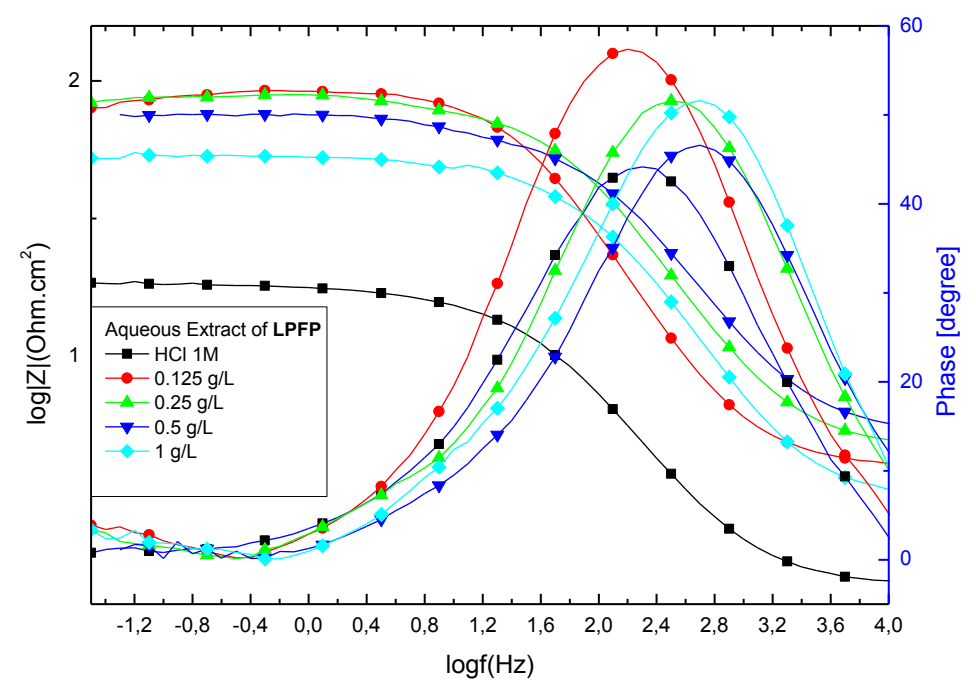

Figure 5: The Bode and phase angle plots for mild steel in $1 \mathrm{M} \mathrm{HCl}$ in the absence and presence of different concentrations of $\boldsymbol{L P F P}$ at $308 \mathrm{~K}$, with an immersion time of 30min

Table 4: EIS parameters for the corrosion of mild steel in $1.0 \mathrm{M} \mathrm{HCl}$ containing aqueous extract of leaves of Pancratium Foetidum Pom at $308 \mathrm{~K}$

\begin{tabular}{|c|c|c|c|c|}
\hline Inhibitor concentration & $\mathbf{R}_{\mathbf{c t}}\left(\mathbf{O h m . \mathbf { c m } ^ { 2 } )}\right.$ & $\begin{array}{c}\mathbf{f}_{\max } \\
(\mathbf{H z})\end{array}$ & $\mathbf{C}_{\mathbf{d l}}\left(\boldsymbol{\mu} \mathbf{F} / \mathbf{c m}^{\mathbf{2}}\right)$ & $\begin{array}{c}\mathbf{E}_{\mathbf{R p}} \\
(\mathbf{\%})\end{array}$ \\
\hline $\mathbf{H C l ~ 1 M}$ & 21.08 & 100 & 75.5 & - \\
\hline $\mathbf{0 . 1 2 5} \mathbf{g} / \mathbf{L}$ & 237.6 & 10 & 66.98 & 91.12 \\
\hline $\mathbf{0 . 2 5} \mathbf{g} / \mathbf{L}$ & 247.2 & 10 & 64.38 & 91.47 \\
\hline $\mathbf{0 . 5} \mathbf{g} / \mathbf{L}$ & 266.4 & 10 & 59.74 & 92.08 \\
\hline $\mathbf{1 ~ g / L ~}$ & 448.8 & 10 & 35.46 & $\underline{\mathbf{9 5 . 3}}$ \\
\hline
\end{tabular}

From the electrochemical impedance parameters and the inhibition efficiency $\left(\mathrm{E}_{\mathrm{Rp}} \%\right)$ which listed in Table 4, it is clear that the impedance spectra exhibit one single capacitive loop, indicating that the charge transfer takes place at the electrode/solution interface, the transfer process controls corrosion reaction and the presence of inhibitor does not change the mechanism of steel dissolution [30].

As the inhibitor concentration increased, the $R_{c t}$ values increased and the $C_{d l}$ values tended to decrease due to a decrease in local dielectric constant and/or an increase in the thickness of the electrical double layer, suggesting that the inhibitor molecules acted by adsorption at the metal/solution interface. Addition of aqueous extract studied provided lower $\mathrm{C}_{\mathrm{dl}}$ values, probably because of replacement of water molecules by inhibitor molecule at the electrode surface. In addition, the inhibitor molecules may reduce the capacitance by increasing the double layer thickness according to the Helmholtz model:

$$
\delta_{\text {org }}=\frac{\varepsilon_{0} \varepsilon A}{C_{d l}}
$$

where $\varepsilon$ is the dielectric constant of the medium, $\varepsilon_{0}$ is the vacuum permittivity, A is the electrode surface area and $\delta_{\text {org }}$ is the thickness of the protective layer.

The data in Table 4 reveal that the values of inhibition efficiency obtained by EIS are comparable to those obtained by potentiodynamic measurement. 
Figure 5 illustrates the Bode and phase angle plots for mild steel in $1 \mathrm{M} \mathrm{HCl}$ in the absence and presence of different concentrations of inhibitor studied at $308 \mathrm{~K}$, with an immersion time of 30min. When analyzing the Nyquist diagrams, it seems that these curves consist of a depressed capacitive loop semicircle with one capacitive time constant in Bode-phase plots for all compounds study.

\subsection{Weight loss study}

\subsubsection{Effect of inhibitor concentration}

Table 5 shows the results obtained from weight loss measurements for mild steel in $1.0 \mathrm{M} \mathrm{HCl}$ solutions in the absence and presence of different concentrations of aqueous extract of Pancratium Foetidum Pom. We observe from the results, that the E\% of aqueous extract increases from $92.57 \%$ to $98.01 \%$ with the increase in inhibitor concentration from 0.125 to $1 \mathrm{~g} / \mathrm{L}$. Indeed, corrosion rate values of mild steel decreases from 0.32 to 0.0063 $\mathrm{mg} / \mathrm{cm}^{2} . \mathrm{h}$. The increase in efficiency may be due to the blocking effect of the surface by adsorption, film formation mechanisms and can be attributed to the increase of the covered surface $(\theta)$ which decreases the effective area of corrosion attack [31]. The results confirm that the aqueous extract of leaves of Pancratium Foetidum Pom is an efficient corrosion inhibitor. The high efficiency is probably due to the synergistic or antagonistic effects of the various constituents of the aqueous extract studied.

Table 5: Weight loss values of various concentrationsof aqueous extract of leaves of Pancratium Foetidum Pom (LPFP) at $308 \mathrm{~K}$ in $1.0 \mathrm{M} \mathrm{HCl}$ solution

\begin{tabular}{|c|c|c|c|}
\hline Concentrations & $\mathbf{C}_{\mathbf{R}}\left(\mathbf{m g} / \mathbf{c m}^{\mathbf{2}} \mathbf{. h}\right)$ & $\mathbf{\Theta}$ & $\begin{array}{c}\mathbf{E} \\
\mathbf{\%}\end{array}$ \\
\hline $\mathbf{H C l}(\mathbf{1 M})$ & 0.32 & --- & -- \\
\hline $\mathbf{0 . 1 2 5} \mathbf{g} / \mathbf{L}$ & 0.0237 & 0.92 & 92.57 \\
\hline $\mathbf{0 . 2 5} \mathbf{g} / \mathbf{L}$ & 0.0204 & 0.93 & 93.62 \\
\hline $\mathbf{0 . 5} \mathbf{g} / \mathbf{L}$ & 0.0162 & 0.94 & 94.93 \\
\hline $\mathbf{1} \mathbf{g} / \mathbf{L}$ & 0.0063 & 0.98 & 98.01 \\
\hline
\end{tabular}

\subsection{Influence of Temperature}

The study of the influence of temperature on the rate of corrosion inhibition of mild steel by our inhibitor (aqueous extract of leaves of Pancratium Foetidum Pom) was performed at temperatures 318, 328,338 and 348 $\mathrm{K}$ in the absence and in the presence of inhibitor at $1 \mathrm{~g} / \mathrm{L}$, to determine the activation energies, enthalpies and entropies of activation of the corrosion process and thus provides information on the mechanism of inhibition. The corresponding data are shown in table 6. The comparative studyof table6 showed thatthe corrosion rateincreases withincrease in temperaturein boththeinhibited solutionsand uninhibited, while the efficiencyof inhibiting(aqueous extract of leaves of Pancratium Foetidum Pom) product decreases slightly. A decrease inthe efficiency ofinhibitionwith increasingtemperature in the presenceof our compoundmay be due tothe weakening ofphysical adsorption.

Table 6: Various corrosion parameters for steel in $1.0 \mathrm{M} \mathrm{HCl}$ in absence and presence of optimum concentration of aqueous extract of leaves of Pancratium Foetidum Pom (LPFP) at different temperatures

\begin{tabular}{|c|c|c|c|}
\hline Temperature (K) & Inhibitor & $\mathbf{C R}\left(\mathbf{m g} / \mathbf{c m}^{2} \mathbf{. h}\right)$ & $\mathbf{E ~ ( \% )}$ \\
\hline \multirow{2}{*}{318} & HCl 1M & 2.0649 & - \\
\cline { 2 - 4 } & Aqueous Extract & 0.1519 & $\underline{\mathbf{9 2 . 6 4}}$ \\
\hline \multirow{2}{*}{328} & HCl 1M & 4.0689 & - \\
\cline { 2 - 4 } & Aqueous Extract & 0.426 & $\underline{\mathbf{8 9 . 5 3}}$ \\
\hline \multirow{2}{*}{338} & HCl 1M & 6.9998 & - \\
\cline { 2 - 4 } & Aqueous Extract & 0.8889 & $\underline{\mathbf{8 7 . 3}}$ \\
\hline \multirow{2}{*}{348} & HCl 1M & 9.7914 & $\underline{\mathbf{8 4 . 9 2}}$ \\
\cline { 2 - 4 } & Aqueous Extract & 1.4765 & \\
\hline
\end{tabular}


To determinethe Ea, we use the Arrhenius equation:

$$
C_{R}=A \exp \left(-\frac{E_{a}}{R T}\right)
$$

It's used to account fortheeffect of temperature $(\mathrm{T})$ onthe corrosion $\operatorname{rate}\left(\mathrm{C}_{\mathrm{R}}\right)$, thechange in the logofcorrosion rateas a functionof the reciprocal ofthe absolute temperature isa linear function of $\mathrm{T}^{-1}$. The corresponding relationprovides accessto theactivation energies:

$$
\operatorname{Ln} C_{R}=-\frac{E_{a}}{R T}+L \mathrm{n} A
$$

To access theactivationthermodynamic characteristics, enthalpy $\left(\Delta \mathrm{H}_{\mathrm{a}}\right)$ andentropy ofactivation $\left(\Delta \mathrm{S}_{\mathrm{a}}\right)$, we used theArrheniusequationtransition[32]:

$$
C_{R}=\frac{R T}{N h} \exp \left(\frac{\Delta S_{a}}{R}\right) \exp \left(-\frac{\Delta H_{\mathrm{a}}}{R T}\right)
$$

where $C_{R}$ is the corrosion rate, $R$ the gas constant, $T$ the absolute temperature, $A$ the pre-exponential factor, $h$ the Plank's constant and $\mathrm{N}$ is Avogrado's number, $\mathrm{E}_{\mathrm{a}}$ the activation energy for corrosion process, $\Delta H_{\mathrm{a}}$ the enthalpy of activation and $\Delta S_{\mathrm{a}}$ the entropy of activation.

The curves ofvariation of the logarithm ofthe corrosion rateas a functionof the reciprocal ofthe absolute temperature $\left(\mathrm{T}^{-1}\right)$ is recordedin (Figure 6). Thatthe curves obtainedin the formof lines.

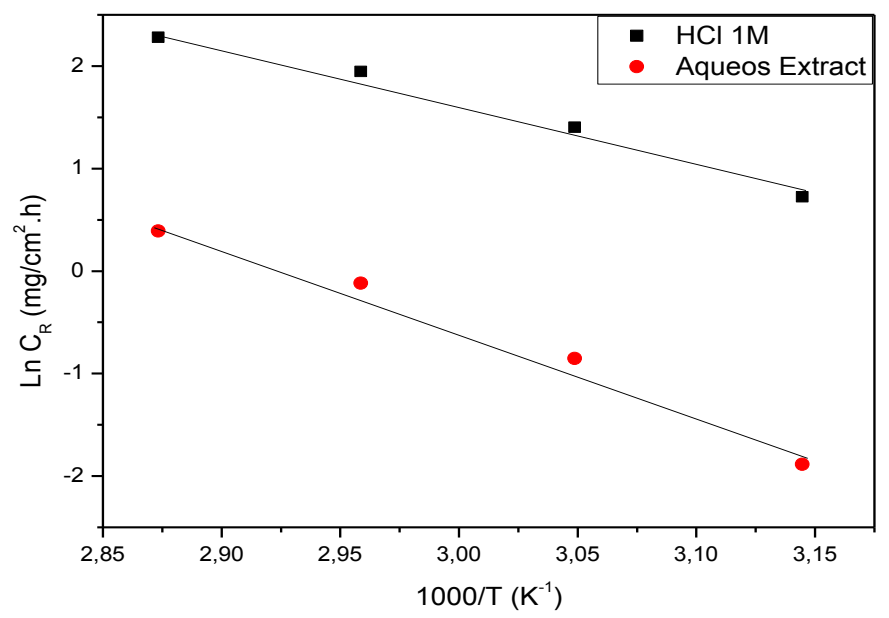

Figure 6: Arrhenius plots of $\mathrm{Ln} \mathrm{C}_{\mathrm{R}} \mathrm{vs} .1 / \mathrm{T}$ for steel in $1.0 \mathrm{M} \mathrm{HCl}$ in the absence and the presence of (Aqueous leaves Extract) at optimum concentration

Figure 7 shows the variation of $\mathrm{Ln}\left(\mathrm{C}_{\mathrm{R}} / \mathrm{T}\right)$ function $(1 / \mathrm{T})$ as a straight line with a slope of $\left(-\Delta \mathrm{H}_{\mathrm{a}} / \mathrm{R}\right)$ and the intersection with the y-axis is $\left[\mathrm{Ln}(\mathrm{R} / \mathrm{Nh})+\left(\Delta \mathrm{S}_{\mathrm{a}} / \mathrm{R}\right)\right]$. From these relationships, values of $\Delta \mathrm{S}_{\mathrm{a}}$ and $\Delta \mathrm{H}_{\mathrm{a}}$ can be calculated. The activation parameters $\left(\mathrm{E}_{\mathrm{a}}, \Delta \mathrm{H}_{\mathrm{a}}\right.$ and $\left.\Delta \mathrm{S}_{\mathrm{a}}\right)$ calculated from the slopes of Arrhenius lines in the absence and presence of our inhibitor are summarized in table 7.

It is clear from table 7 that the value of the apparent activation energy for the inhibited solution was higher (69.81 $\mathrm{kJ} / \mathrm{mol}$ ) than that for the uninhibited solution $(48.13 \mathrm{~kJ} / \mathrm{mol})$, indicating that the dissolution of mild steel was decreased due to formation of a barrier by the adsorption of the inhibitors on metal surface [7].

The values of $\mathrm{E}_{\mathrm{a}}$ and $\Delta \mathrm{H}_{\mathrm{a}}$ were increased in the presence of inhibitor, suggesting that the energy barrier of the corrosion reactionincreases, meaning that the dissolution of the steel is difficult [33]. According Gomma et al [34], the activation energy is much higher than the inhibitor is more effective. However, the positive sign of the endothermic enthalpy reflects the nature of the dissolution of the steel. We note that the variation of the activation energy $\mathrm{E}_{\mathrm{a}}$ and the enthalpy of $\Delta \mathrm{H}_{\mathrm{a}}$ vary in the same way with the concentration of inhibitor, which satisfies the relationship between $\mathrm{E}_{\mathrm{a}}$ and thermodynamics as $\Delta \mathrm{H}_{\mathrm{a}}: \mathrm{E}_{\mathrm{a}}-\Delta \mathrm{H}_{\mathrm{a}}=\mathrm{RT}$ [35]. 


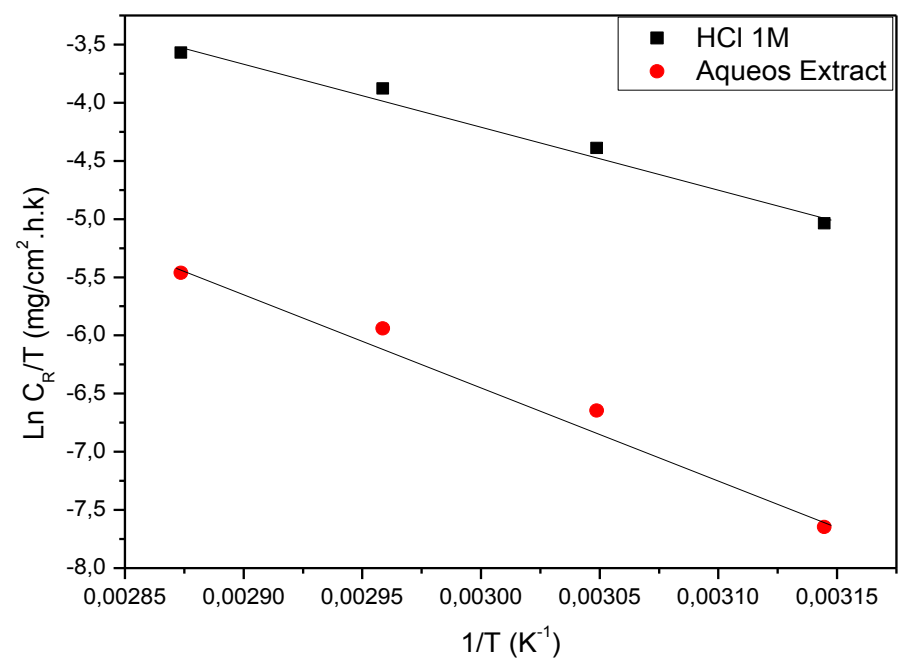

Figure 7: Arrhenius plots of $\mathrm{Ln}\left(\mathrm{C}_{\mathrm{R}} / \mathrm{T}\right)$ vs. $1 / \mathrm{T}$ for steel in $1.0 \mathrm{M} \mathrm{HCl}$ in the absence and the presence of (Aqueous extract) at optimum concentration

Table 7: Activation parameters for the steel dissolution in $1.0 \mathrm{M} \mathrm{HCl}$ in the absence and the presence of (aqueous of leaves extract) at $1 \mathrm{~g} / \mathrm{L}$

\begin{tabular}{|c|c|c|c|c|}
\hline Inhibitor & $\begin{array}{c}\boldsymbol{E}_{\mathrm{a}} \\
(\mathrm{kJ} / \mathrm{mol})\end{array}$ & $\begin{array}{c}\Delta \mathbf{H}_{\mathrm{a}}^{\circ} \\
(\mathrm{kJ} / \mathrm{mol})\end{array}$ & $\begin{array}{c}\Delta \mathbf{S}_{\mathrm{a}}^{\circ} \\
(\mathrm{J} / \mathrm{mol} . \mathrm{K})\end{array}$ & $\begin{array}{c}\mathbf{E}_{\mathrm{a}}-\Delta \mathbf{H}_{\mathbf{a}} \\
(\mathrm{KJ} / \mathrm{mol})\end{array}$ \\
\hline $\mathrm{HCl} 1 \mathrm{M}$ & 48.13 & 45.36 & -96.27 & 2.77 \\
\hline Aqueous Extract & 69.81 & 67.05 & -49.37 & 2.76 \\
\hline
\end{tabular}

The value of $\Delta \mathrm{S}_{\mathrm{a}}$ was lower for the uninhibited solution than that for the solution with inhibitor. This might be attributed to the rate-determining step for the activated complex was the association rather than the dissociation step [36]. As seen from Table 7, the shift of $\Delta \mathrm{S}_{\mathrm{a}}$ to more positive values in the presence of the inhibitor, thus the increase in disorder, is a driving force that can overcome the barriers for the adsorption of inhibitor onto the metal surface.

\section{Conclusion}

The following remarks can be made:

- There is a relationship between the total polyphenol, flavonoid content and antioxidant activity.

- Aqueous extract of PancratiumFoetidum Pom leaves (LPFP), has a moderate antioxidant activity.

- Tafel polarization measurements indicate that the aqueous extract of leaves of Pancratium Foetidum Pom (LPFP) act essentially as a mixed type inhibitor.

- The increase in the charge transfer resistance and decrease in double layer capacitance values, with the increase in the inhibitor concentration, showed that the aqueous extract of Pancratium Foetidum Pom formed protective layers on the mild steel surface, covering areas where $\mathrm{HCl}$ solution degrades and corrodes rapidly.

- Inhibition efficiency increases with increase in the concentration of aqueous extract but decreases slightly with rise in temperature.

- Results obtained through weight loss measurements and electrochemical tests demonstrated that the aqueous extract of leaves of Pancratium Foetidum Pom act as efficient corrosion inhibitor of the mild steel in $1 \mathrm{M}$ $\mathrm{HCl}$ solution.

- Several authors have shown great interest in corrosion by using plant extracts (extracts and essential oils) as corrosion inhibitors in $\mathrm{HCl}$ medium, the added value of our work is that we obtained a very high efficiency using a very low concentration $(0.125 \mathrm{~g} / \mathrm{L} \rightarrow 92.57 \%)$ of the extract studied. 


\section{References}

1. Deysson G., Systematic second part. Edition Sedes.

2. Jahandiez L., Maire R., I (1931), II (1932), III (1934).

3. Elmsellem H., Aouniti A., Toubi Y., Steli H., Elazzouzi M., Radi S., Elmahi B., El Ouadi Y., Chetouani A., Hammouti B., Der Pharma Chem. 7 (2015) 353-364.

4. El Ouadi Y., Elmsellem H., El fal M., Sebbar N.K., Bouyanzer A., Rmili R., Essassi E.M., El Mahi B., Majidi L., Hammouti B., Der Pharma Chem. 8 (2016) 365-373.

5. Cherrak K., Dafali A., Elyoussfi A., El Ouadi Y., Sebbar N.K., El Azzouzi M., Elmsellem H., Essassi E.M., Zarrouk A., J. Mater. Environ.. Sci 8 (2017) 636-647

6. Elalaoui Belghiti M., Nahlé A., Ansari ?., Karzazi Y., Tighadouini S., El Ouadi Y., Dafali A., Hammouti B., Radi S., Anti-Corros. Methods Mater. 64 (2017) 23-35

7. El Ouadi Y., Abrigach F., Bouyanzer A., Touzani R., El Assyry A., Zarrouk A., Hammouti B., Port. Electrochim. Acta 35 (2017) 159-178.

8. El Ouadi Y., Bouyanzer A., Majidi L., Paolini J., Desjobert J.M.,Costa J., Chetouani A., Hammouti B., Jodeh S., Warad I., Mabkhot Y., Ben Hadda T., Res. Chem. Intermed. 41 (2015) 7125-7149.

9. Manssouri M., El Ouadi Y., Znini M., Costa J., Bouyanzer A., Desjobert J.M , Majidi L., J. Mater. Environ. Sci. 6 (2015) 631-646.

10. Bendaif H., Melhaoui A., El Azzouzi M., Legssyer B., Hamat T., Elyoussfi A., Aouniti A., El Ouadi Y., Aziz M., J. Mater. Environ. 7 (2016) 1276-1287.

11. Nahlé A., El Ouadi Y., Bouyanzer A., Lhou M., Paolini J., Desjobert J.M., Costa J., Chahboun N., Zarrouk A., Hammouti B., Orient. J. Chem. 32 (2016) 1909-1921.

12. Di Majo D., La Guardia M., Giammanco S., La Neve L., Giammanco M., Food Chem. 111 (2008) 45-49.

13.Georgieva S., Boyadzhiev L., Angelov G., Ind. Engineering Rev. 5 (2010) 124-132.

14. Marc Fr., Davin A., Deglène-Benbrahim L., Ferrand C., Erudit M / S: Medicine Sciences. 20 (2004) 458-463.

15. El Ouadi Y., Amirou A., Bouyanzer A., Elmsellem H., Majidi L., Bouhtit F., Hammouti B., Maghr. J. Pure \& Appl. 1 (2015) 18-24.

16. Naceiri Mrabti H., Marmouzi I., Sayah K., Chemlal L., El Ouadi Y., Elmsellem H., Cherrah Y., Faouzi My A., J. Mater. Environ. 8 (2017) 217-224.

17. El Ouadi Y., Bendaif H., Mrabti H.N., Elmsellem H., Kadmi Y., Shariati M.A., Abdel-Rahman I., Hammouti B., Bouyanzer A., J. Microbiol. Biotech Food. 6 (2017) 1218-1220.

18. Graham H.D., J. Agric. Food Chem. 40 (1992) 801-805.

19. Boizot N., Charpentier J.P., Le cahier des techniques de 1'Inra. (2006) 79-82.

20. Bahorun T., Gressier B., Trotin F., Brunete C., Dine T., Vasseur J., Gazin J.C., Pinkas M., Luycky M., Gazin M., Arzneimittel-Forschung 46 (1996) 1086-1089.

21. Arvouet-Grand A., Vennat B., Pourrat A., Legret P., J. Pharm. Belg. 49 (1994) 462-468.

22. Hatano T., Kagawa H., Yasuhara T., Okuda T., Chem. Pharm. Bull. 36 (1985)1090-1097.

23. Brand-Williams W., Cuvelier M. E., Berset C., activity.Food. Technol. 28(1995) 25-30

24. Brand-Williams W., Cuvelier M.E., Berset C., Lebensm. -Wiss., Technol. 28 (1995) 25-30.

25. Bastida J., Contreras J.L., Codina C., Wright C.W., Philipson D., Phytochemistry. 40 (1995) 1549-1551.

26. Orhan I. E., Yilmaz B. S., Altun M. L., Saltan G., Şener B., Rec. Nat. Prod. 5 (2011) 193-201.

27. Li X., Deng S., Fu H., Mu G., Corros. 51 (2009) 620-634.

28. Deyab M.A., Abd El-Rehim S.S., Keera S.T., Colloids Surf. A 348 (2009) 170-176.

29. Haruyama S., Tsuru T., Gijutsu B., J. Jpn. Soc. Corros. Eng. 27 (1978) 573-581.

30. Ramesh Saliyan V., Airody Vasudeva Adhikari., Corros. 50 (2008) 55.

31. Zhao T.P., Mu G.N., Corros. 41 (1999) 1937.

32. Bockris J. O'M., A. K. N. Reddy A. K. N., Modern. Electrochem. 2 (1977) 1267.

33. Dehri I., Özcan M., Mater. Chem. Phys. 98 (2006) 316-323.

34.Gomma G.K., Wahdan M.H., Mater. Chem. Phys. 39 (1995) 209-213.

35. Guan N.M., Xueming L., Fei L., Mater. Chem. Phys. 86 (2004) 59-68.

36. Li X., Deng S., Fu H., Mu G., Corros. 50 (2008) 2635-2645.

(2017) ; http://www.jmaterenvironsci.com 